\title{
OFICINAS: ESTRATÉGIA METODOLÓGICA PARA A PESQUISA DIALÓGICA COM CRIANÇAS
}

\author{
- REJANE BRANDÃO SIQUEIRA \\ https://orcid.org/0000-0002-9927-3396 \\ Pontifícia Universidade Católica do Rio de Janeiro \\ ROSIANE BRANDÃO SIQUEIRA ALVES \\ https://orcid.org/0000-0001-6533-7745 \\ Pontifícia Universidade Católica do Rio de Janeiro
}

RESUMO Este artigo objetiva apresentar apontamentos do percurso de pesquisa em uma das seis instituições educativas que integram o campo de pesquisa institucional que buscou conhecer e compreender as concepções de cuidar e ser cuidado de profissionais, crianças e responsáveis em escolas de educação infantil e ensino fundamental. Traz um recorte com breve descrição do desenvolvimento dos dispositivos metodológicos nos quais, a partir dos estudos da filosofia da linguagem de Bakhtin (1992a; 1992b; 2011), a linguagem é tomada como centro do processo, e destaca a realização de oficina com crianças de cinco anos de idade em uma Escola Municipal de Educação Infantil (Emei). A partir de seu referencial teórico, a pesquisa assume uma concepção de cuidado ancorada na filosofia do diálogo de Martin Buber que aponta horizontes para um olhar de reconhecimento, percepção e compreensão do outro.

Palavras-chave: Cuidado. Diálogo. Relação. Metodologia.

\section{ABSTRACT WORKSHOPS: METHODOLOGICAL STRATEGY FOR}

\section{DIALOGICAL RESEARCH WITH CHILDREN}

This article aims to present notes from the research path in one of the six educational institutions that integrate the field of institutional research that sought to know and understand the concepts of caring and being cared for by professionals, children and guardians in schools of Early Childhood Education and Elementary Education. It presents an outline with a brief description of the development of methodological devices in which, based on the studies of the philosophy of language by Bakhtin (1992a; 1992b; 2011), language is taken as the center of the process, and highlights the realization of a workshop 
with children of 5 years old at a Municipal School of Early Childhood Education. Based on its theoretical framework, the research assumes a conception of care anchored in Martin Buber's philosophy of dialogue that points out horizons for a look of recognition, perception and understanding of the other.

Keywords: Care. Dialogue. Relationship. Methodology.

\section{RESUMEN TALLERES: ESTRATEGIA METODOLÓGICA PARA LA INVESTIGACIÓN DIALÓGICA CON NIÑOS}

Este artículo tiene como objetivo presentar apuntes de la trayectoria investigadora en una de las seis instituciones educativas que integran el campo de la investigación institucional que buscó conocer y comprender los conceptos de cuidar y ser atendido por profesionales, niños y tutores en las escuelas de Educación Infantil y Educación Primaria. Presenta un esquema con una breve descripción del desarrollo de dispositivos metodológicos en los que, a partir de los estudios de la filosofía del lenguaje de Bakhtin (1992a; 1992b; 2011), se toma el lenguaje como centro del proceso, y se destaca la realización de un taller con niños de 5 años en una Escuela Municipal de Educación Infantil. A partir de su marco teórico, la investigación asume una concepción del cuidado anclado en la filosofía del diálogo de Martin Buber que señala horizontes para una mirada de reconocimiento, percepción y comprensión del otro.

Palabras clave: Atención. Diálogo. Relación. Metodología.

\section{Introdução}

Existem duas maneiras básicas de influenciar os homens no seu modo de pensar e na sua forma de viver. Na primeira, a pessoa quer se impor a si própria, impor a sua opinião de atitude [...]. Na segunda maneira básica de agir sobre o outro, a pessoa quer encontrar também na alma do outro, como nela instalado, e incentivar aquilo que em si mesmo ele reconheceu como certo; já que é o certo, então deve estar vivo no microcosmo do outro como possibilidade dentre outras possibilidades; o outro deve apenas abrir-se nesta sua potencialidade e esta abertura dá-se essencialmente não através de um aprendizado, mas através do encontro, através da comunicação existencial entre um ente que é e um outro que pode vir a ser. A primeira maneira desenvolveu-se com mais intensidade no campo da propaganda, a segunda no da educação. (BUBER, 2014, p. 149-150).
Este artigo apresenta apontamentos do percurso teórico-metodológico de pesquisa institucional ${ }^{1}$ desenvolvida a fim de conhecer e compreender as concepções de cuidar e ser cuidado de profissionais, crianças e responsáveis em seis instituições educativas do Rio de Janeiro, através da utilização dos seguintes dispositivos metodológicos: observações, entrevistas individuais e coletivas com os adultos, oficinas utilizando a literatura infantil com as crianças.

1 Pesquisa "Linguagem e rememoração: crianças, famílias, professores/as e suas histórias" desenvolvida pelo grupo Infância, Formação e Cultura (INFOC) da Pontifícia Universidade Católica do Rio de Janeiro (PUC-Rio) sob a coordenação das professoras Sonia Kramer, Maria Fernanda Nunes e Alexandra Pena com o apoio do Conselho Nacional de Desenvolvimento Científico e Tecnológico (CNPq) e da Fundação de Amparo à Pesquisa do Estado do Rio de Janeiro (Faperj). 
A escolha das instituições foi orientada pela busca de práticas positivas de cuidado identificadas a partir de critérios como familiaridade, indicação e Índice de Desenvolvimento da Educação Básica (Ideb). Inicialmente, a busca por práticas positivas de cuidado e seus sujeitos foi consolidada em observações do cotidiano de seis instituições públicas duas creches; duas pré-escolas; duas escolas de ensino fundamental - que atendem à educação infantil e/ou anos iniciais do ensino fundamental.

A concepção de cuidado assumida na pesquisa está ancorada na filosofia do diálogo de Martin Buber (2014), que aponta horizontes para um olhar de reconhecimento, percepção e compreensão do outro conforme texto em epígrafe; e a linguagem, abordada como centro do processo teórico metodológico, se fundamenta nos estudos da filosofia da linguagem de Mikhail Bakhtin (1992a; 1992b; 2011).

A abordagem ora apresentada aponta o percurso construído no processo de coleta de dados em uma Escola Municipal de Educação Infantil (Emei) situada na Baixada Fluminense do Rio de Janeiro onde foram desenvolvidas observações em salas da aula e demais espaços da escola por um período de cinco meses com registros em cadernos de campo a partir dos quais foram definidos por indicação dos profissionais ou por ações cuidadosas observadas, os sujeitos da pesquisa - duas professoras, duas diretoras, quatro crianças e três responsáveis com quem foram realizadas entrevistas individuais (profissionais e familiares) e oficina (crianças) mediada pela literatura infantil.

O texto está dividido em três seções. Inicialmente, são apresentadas considerações históricas do atendimento à criança pequena abordando o caráter dual que o caracteriza a fim de identificar a incorporação do binômio educar e cuidar ao trabalho educativo da pri- meira etapa da educação básica; em seguida, é explicitado o referencial teórico-metodológico que orientou a pesquisa; e, por fim, delineia-se o percurso da construção da oficina desenvolvida com as crianças em um dos campos da pesquisa.

\section{Educar e cuidar: um binômio indissociável?}

No contexto brasileiro, o atendimento escolarizado às crianças pequenas acontece em intuições educativas organizadas por faixa etária de acordo com a Lei de Diretrizes e Bases da Educação Nacional (LDBEN) no 9394/96 (BRASIL, 1996), desse modo, as crianças de zero a três anos são atendidas em creches e aquelas de quatro e cinco anos na pré-escola e ambas constituem a primeira etapa da educação básica, ou seja, a educação infantil.

Historicamente, a construção social desse atendimento é marcada por tensões que se revelam na maneira de conceber a criança e sua educação de forma que, por um longo período as instituições educativas foram caracterizadas por práticas comprometidas com a sua guarda e sobrevivência. Nesse contexto, a concepção de cuidado assumida se relacionava diretamente à higiene e à alimentação.

No Brasil, esse atendimento assume diferentes facetas. Nos séculos XIX e XX, destacase uma dualidade associada à classe social atendida, ou seja, surgem os jardins da infância com ênfase no processo educativo e com base em uma proposta pedagógica froebeliana para as camadas mais abastadas, em contrapartida, os asilos e internatos para crianças abandonadas e desafortunadas com ênfase no cuidado com a higiene e a saúde. (KUHLMANN JR, 2001; 2004).

A pedagogia das instituições educacionais para os pobres é uma pedagogia da submissão, uma educação assistencialista marcada pela ar- 
rogância que humilha para depois oferecer o atendimento como dádiva, como favor aos poucos selecionados para receber. Uma educação que parte de uma concepção preconceituosa da pobreza, por meio de um atendimento de baixa qualidade, pretende preparar os atendidos para permanecer no lugar social a que estariam destinados. (KUHLMANN JR., 2004, p. 182).

Em uma lógica da construção da nação, no momento em que o Brasil é proclamado República, emerge a preocupação com a alta mortalidade infantil e com os filhos dos (ex) escravos que se imprime em iniciativas filantrópicas isoladas de assistência e proteção à infância, especificamente à criança pobre.

Já na década de 1930, com as transformações, quanto ao modelo político econômico, instauradas pelo advento do Estado Novo, a criança assume lugar central nos discursos do Estado que passa a defender o seu atendimento com veemência, enfatizando a sua relação com a pátria para a formação de uma raça forte e sadia. A criança passa então a ser valorizada enquanto "matriz do homem" e redentora da pátria, sem, entretanto, reparar a sua inserção na sociedade de classes e reproduzindo a imagem de um estado harmônico, ou seja, sem conflitos ou interesses de classe. (KRAMER, 2011, p. 56).

Quanto às questões educacionais, entre os anos 1930 e 1980, o atendimento pré-escolar passou a contar com a participação direta do setor público, e os discursos oficiais do atendimento às classes populares se caracterizavam inicialmente pela assistência médico-pedagógica, nutricional e social e, posteriormente, educacional, associando a criança ao desenvolvimento da nação e, diante disso, importantes órgãos foram criados e voltados à organização do seu atendimento, ora comprometidos com a compensação de suas carências, ora preparatórios para as etapas posteriores, sem, contudo, perder o caráter dual demarcado pela divisão de classes. Quanto a esse período, Sonia Kramer (2011) discorre que, nesses 50 anos, os discursos oficiais relacionavam permanentemente a assistência médico-pedagógica à criança com o desenvolvimento da nação.

O processo de urbanização do país somado a maior participação da mulher no mercado de trabalho e a pressão dos movimentos sociais por espaços de atendimento à criança marcam um período de expansão do atendimento educacional, principalmente na faixa etária de quatro a seis anos quando a pré-escola passa a ser compreendida como preparatória para a escolarização com o objetivo de defender a estimulação cognitiva, além do preparo para a alfabetização. 0 dualismo, no entanto, se mantém: às crianças das camadas mais pobres é oferecido um atendimento pautado por práticas assistencialistas e/ou compensatórias, enquanto às das classes abastadas era garantido o acesso à instituições que objetivavam a sua educação, instrução e desenvolvimento.

Refletindo o panorama político do país, aos finais do século XX, se fortalece a proposta de um sistema democrático de governo e novos modos de conceber a criança são construídos sob a influência de documentos e acordos internacionais, dentre os quais se destaca a Declaração Universal dos Direitos da Criança (UNICEF, 1959), que contribuiu para trazer à cena os direitos da criança e do adolescente.

No bojo dessas transformações, à criança brasileira é delegado um novo papel social - sujeito de direitos - impresso no texto da Constituição Federal de 1988 (BRASIL,1988) e, posteriormente, consolidado no Estatuto da Criança e do Adolescente (ECA) Lei no 8069 (BRASIL, 1990). E entre os direitos de toda criança está o direito à educação desde o seu nascimento materializado no texto da LDBEN no 9394/96 (BRASIL, 1996) que organiza a educação institucionalizada para todas as crianças a partir de zero a seis anos de idade na 
educação infantil, cuja finalidade é promover o seu desenvolvimento integral ${ }^{2}$ em seus aspectos físico, psicológico, intelectual e social. E é nesse contexto que se insere a concepção do binômio educar e cuidar.

De acordo com Campos (1994, apud KRAMER, 2005, p. 60), a expressão conjunta “cuidar e educar" surge nos Estados Unidos onde, com a intenção de unir cuidar (care) e educar (educate), foi forjado o termo "educare" e não havendo correspondente na língua portuguesa, o uso do binômio educar e cuidar se tornou mais adequado para o que estava sendo realizado na educação infantil brasileira e se imprime no texto das Diretrizes Curriculares Nacionais (DCNs).

As Instituições de Educação Infantil devem promover em suas Propostas Pedagógicas, práticas de educação e cuidados, que possibilitem a integração entre os aspectos fisicos, emocionais, afetivos, cognitivo/linguísticos e sociais da criança, entendendo que ela é um ser completo, total e indivisivel. (BRASIL,1999).

Trata-se, portanto, de uma mudança de concepção do atendimento em que, agora entendido como educação infantil, ou seja, etapa educativa, deixa de consistir em caridade, assistência ou compensação e passa a se caracterizar direito educacional de toda criança. Essa nova concepção marca um período de lutas, conquistas, perdas, avanços e retrocessos num processo - ainda em curso - de consolidação da cobertura do atendimento e, principalmente, da qualidade em que educar e cuidar deve ser entendido como binômio indissociável.

Nesse sentido, as últimas décadas do século XX e início do século XXI marcam historicamente as mais expressivas mudanças no que

2 A faixa etária de atendimento na educação infantil sofreu alteração em 2006, quando a Lei no 11.274 regulamentou o ensino fundamental de nove anos e, diante disso, a criança de seis anos passou a ser atendida no ensino fundamental. se refere à concepção de criança, à sua educação e ao seu reconhecimento como sujeito de direitos.

A partir disso, a educação infantil é direito de todas as crianças no Brasil e a sua oferta, responsabilidade dos municípios. Contudo, cumprindo o seu papel de orientador e formulador das políticas, o governo federal através do Ministério da Educação (MEC) oferece uma série de documentos orientadores e norteadores da construção de propostas e práticas de educação infantil (BRASIL, 1998; 1999; 2006a; 2006b; 2009) que passam a ter o educar e cuidar como binômio indissociável.

Dos documentos orientadores, destacamos as DCNs para a educação infantil revisadas em 2009 (BRASIL, 2009), e com caráter mandatório estabelece em seu artigo $8^{\circ}$ que as propostas pedagógicas das instituições de educação infantil devem ter como objetivo garantir à criança o acesso a processos de apropriação, renovação e articulação de conhecimentos e aprendizagens de diferentes linguagens, assim como o direito à proteção, à saúde, à liberdade, à confiança, ao respeito, à dignidade, à brincadeira, à convivência e à interação com outras crianças.

$\S 1$ ㅇ Na efetivação desse objetivo, as propostas pedagógicas das instituições de Educação Infantil deverão prever condições para o trabalho coletivo e para a organização de materiais, espaços e tempos que assegurem:

I - a educação em sua integralidade, entendendo o cuidado como algo indissociável ao processo educativo; (BRASIL, 2009).

Essa definição coaduna com o que fora apontado por Kramer ${ }^{3}$ quando afirma:

3 Edição e revisão do texto final de entrevista concedida à Márcia Buss Simão e Moema Kiehn do Núcleo de Estudos e Pesquisas da Educação na Pequena Infância (Nupein), realizada pelo prof. João Josué da Silva Filho. Disponivel em: periodicos.ufsc.br > index.php > zeroseis > article > download. Acesso em: 20 de abril de 2020 . 
[...] educar envolve cuidar e ensinar, o que eu acho que foi um equívoco, essa polarização que se fez, de cuidar versus educar, essa polarização, o que nós deveríamos ter feito era entre o cuidar e o ensinar. Na realidade o educar não se opõe, ao cuidar, inclui o cuidar, ou seja, no campo da educação infantil, parece que eu cuido mais dos bebês do que das crianças maiores, isso obviamente é verdade, do ponto de vista prático, mas eu preciso dizer, que eu cuido sempre! (2008, p. 9-10).

Entender que crianças são sujeitos da história e da cultura, além de serem por elas produzidos, implica ver o processo pedagógico na sua dimensão cultural, como conhecimento, arte e vida, e essa concepção não pode se restringir à educação infantil, tendo em vista que, nessa etapa, o cuidado no viés assistencialista já foi, em termos da legislação, superado. As considerações de Kramer (2008), portanto, coadunam com as diretrizes e sinalizam para a necessária compreensão da dimensão educativa dessa etapa da educação básica.

Entendido na sua indissociabilidade educar e cuidar é fundamento inerente a todas as etapas da educação básica sendo, portanto, “necessário considerar as dimensões do educar e do cuidar, em sua inseparabilidade, buscando recuperar, para a função social desse nível da educação, a sua centralidade, que é o educando, pessoa em formação na sua essência humana". (BRASIL, 2010) ${ }^{4}$.

Esse é um significativo avanço na perspectiva da formação humana visto que "no processo de educação, em qualquer nível de ensino, cuidamos sempre do outro" (KRAMER, 2003, p. 77), e que, sem cuidado consigo mesmo e com o outro, o homem deixa de ser humano, ou seja, "desestrutura-se, perde sentido e morre, o que significa dizer que é o cuidado que possibilita a existência humana". (BOFF, 1999, p.34).

4 BRASIL. Resolução no 4, de 13 de julho de 2010. Define as Diretrizes Curriculares Nacionais Gerais para a Educação Básica.

\section{Cuidado é relação. Cuidado é diálogo}

Cuidado é relação, é diálogo. Educar e cuidar são indissociáveis quando a educação é encontro, conforme descreve Martin Buber (2014) no texto em epígrafe. Falar de cuidado é falar do humano, é abordar abertura e encontro na comunicação existencial. Cuidado é abrir-se ao outro, entrar em relação e nela constituirse humano e tomar consciência de si. Nesse processo constituinte, as interações são fundamentais.

A constituição do sujeito, entendida de forma contextualizada na história e na cultura, vai sendo significada através do social, em que um influencia e contribui com o outro; e a linguagem, fenômeno social, trama a todas as relações e em todos os domínios, sendo o indicador mais sensivel de todas as transformações sociais. (BAKHTIN, 2011).

A partir desse olhar, um dos caminhos possiveis para o reconhecimento do outro em suas ações e práticas cotidianas é abordá-lo em sua fala que é constituidora dos seres humanos e, nesse processo, os estudos da filosofia da linguagem de Mikhail Bakhtin (2011) possibilitaram abordar a linguagem como centro do processo teórico metodológico da pesquisa que buscou conhecer e compreender concepções de cuidar e ser cuidado presentes nas falas e práticas domésticas e institucionalizadas dos sujeitos.

O movimento básico dialógico em torno do qual se constrói uma atitude essencial consiste em um voltar-se ao outro e o que, embora possa parecer banal, tem a intenção de perceber a presença do outro. Para isso, é preciso o desatar da indiferença. (BUBER, 2014).

Segundo Buber (2014), adentrar a vida dialógica implica o movimento básico de voltarse ao outro e aceitá-lo em sua totalidade. 0 diálogo pode assumir três formas: o diálogo 
autêntico, o diálogo técnico e o monólogo disfarçado de diálogo.

No diálogo autêntico, os participantes se fazem presentes, ou seja, há a intenção de ouvir o outro e não apenas falar. Nesse diálogo, todos estão comprometidos uns com os outros, e se voltam uns aos outros. Já o diálogo técnico, é "movido pela necessidade de entendimento objetivo" (BUBER, 2014, p.54), no qual se mantém uma conversação a fim de se obter explicação. Por outro lado, no monólogo disfarçado de diálogo, o outro não é considerado, não é reconhecido e sua presença é indiferente, é um "fantasma sem rosto" (idem).

Para Bakhtin (1992b), “a compreensão é uma forma de diálogo" e "compreender é opor à palavra do locutor uma contra palavra" ( $p$. 132). Exercer a educação como resposta responsável requer que, no diálogo, ele - o outro - se torne uma primeira pessoa, que também fala e, ao fazê-lo, me torna um Tu, pois aquele que diz "Tu" não tem coisa alguma por objeto, segundo Buber (2001).

Geraldi (2003) considera que o pensamento bakhtiniano está alicerçado nos pilares da alteridade e dialogia tendo a relação por base. Nessa perspectiva, a alteridade pressupõe o outro como existente, ou seja, reconhecido pelo "eu" como outro que não eu; e a dialogia qualifica a relação essencial entre o eu e o outro.

Assumir a relação dialógica como essencial na constituição dos seres humanos não significa imaginá-la sempre harmoniosa, consensual e desprovida de conflitos, pelo contrário, é a habilidade de conjugar a diversidade, que é um dos grandes desafios da educação.

É na relação que se constituem o ser humano e a consciência de si e nesse processo constituinte as interações são fundamentais. (BAKHTIN, 1992a). Sendo assim, a constituição do sujeito é entendida de forma contextualizada, na história e na cultura, e significada atra- vés do social, de maneira que um influencie e contribua com o outro.

Nessa perspectiva, a pesquisa está ancorada na concepção do diálogo como encontro, momento de aproximação entre pessoas nos simples acontecimentos da vida, quando se está aberto às relações, ao reconhecimento do outro e do tempo em que se está com o outro, porque há o encontro entre o "Eu" e o "Tu" na reciprocidade de uma ação vivida na sua inteireza e os sujeitos inteiros nessa ação estabelecem laços, elos, conexões, nos quais um se volta ao outro, vivendo em um mesmo tempo - presente - e em presença. (BUBER, 2001).

Abertura e disponibilidade encontram em Buber (2001) um suporte, a zona de silêncio, na qual se inscreve a confiança no outro. 0 olhar encontra rapidamente o calor e a gratuidade da resposta. Relação é reciprocidade, a atuação é mútua, o Eu/Tu atuam um sobre o outro e o lugar do outro é indispensável para a realização existencial. (ZUBEN, 2001).

Partindo da tipologia dialógica proposta por Buber (2014), das observações das práticas de professores - e demais profissionais - e escuta dos mesmos, foram levantadas as seguintes categorias de pesquisa: I. cuidado autêntico, entendido como interesse pelo outro, não indiferença, responsividade; II. cuidado técnico que se propõe a informar, ensinar, convencer alguém ou, simplesmente, transmitir uma mensagem; III. descuido, em que o outro não é considerado, não é reconhecido e sua presença é indiferente, e IV. descuido disfarçado de cuidado em que a atitude tem formato de cuidado, mas esconde uma indiferença em relação ao outro. (KRAMER, 2019).

\section{A metodologia da pesquisa numa perspectiva dialógica}

O homem transformado em EU que pronuncia o EU-ISSO coloca-se diante das coisas em vez de 
confrontar-se com elas no fluxo da ação recíproca. Curvado sobre cada uma delas, com uma lupa objetivante que olha de perto, ou ordenando-as num panorama através de um telescópio objetivante de um olhar distante, ele as isola ao considerá-las, sem sentimento algum de exclusividade, ou ele as agrupa sem sentimento algum de universalidade. (BUBER, 1974, p. 33).

Uma pesquisa que assume a perspectiva do cuidado como ação humana estabelecida entre os homens é uma pesquisa que se estabelece na relação Eu-Tu/Eu-Isso. (BUBER, 2001). Para Buber, a palavra-princípio "Eu-Tu" fundamenta o mundo da relação e só pode ser proferida pelo ser na sua totalidade, atitude de encontro entre dois parceiros na reciprocidade e na confirmação mútua. Cada "isso" pode, se entrar no evento da relação, tornarse um "Tu" e cada "Tu" em nosso mundo deve tornar-se irremediavelmente um "isso".

Em coerência com o objeto da pesquisa e da escolha de pesquisar práticas positivas de cuidado, de modo a imprimir relevância às possibilidades e potencialidades dos sujeitos e das escolas, o primeiro passo para o desenvolvimento da investigação foi discutir coletivamente nas reuniões semanais do grupo de pesquisa os critérios para a escolha das instituições. Definiu-se pela familiaridade e indicação, ou seja, escolas com profissional/ ais que conheciamos ou que tínhamos notícias de suas boas práticas, e Ideb ${ }^{5}$ com índice mínimo de até sete. Além desses, a localização das instituições foi também considerada a fim de abordar diferentes realidades e um olhar cuidadoso para os pesquisadores sendo observadas as condições de acesso, proximidade e segurança.

5 Índice de Desenvolvimento da Educação Básica, criado em 2007, pelo Instituto Nacional de Estudos e Pesquisas Educacionais Anísio Teixeira (Inep), formulado para medir a qualidade do aprendizado nacional e estabelecer metas para a melhoria do ensino. Ver: http://portal.mec.gov.br.
Definidos os critérios, numa perspectiva de cuidado com os possíveis campos de pesquisa, organizado em duplas ou trios, o grupo visitou as instituições com o objetivo de apresentar a pesquisa e consultar a disponibilidade de acolhimento, além de ter uma primeira impressão sobre a escola construindo, desse modo, um movimento norteado pela busca de empatia (BUBER, 2004) entre pesquisador e pesquisados:

Introduzir-se com o próprio sentimento em algo, na estrutura dinâmica de um objeto, de uma coluna, de uma árvore, de um ramo de árvore, e inclusive de uma criatura animal ou humana, e procurá-las desde dentro, compreendendo a forma e a agitação do objeto com as próprias sensações musculares, transplantarse ali, interiormente (sentir o que o outro sente com o próprio corpo). Significa exclusão da própria concretude, extinção da situação vivida, cessação da realidade na qual se participa de forma puramente estética. (BUBER, 2004, p. 25) ${ }^{6}$

Reconhecendo a abertura da instituição à universidade como uma relação dialógica, em que a escola é o "Eu" e a universidade é "isso", o primeiro movimento foi feito em nome do grupo de pesquisa com vistas a compreender e ser compreendido. Foram visitas que se consolidaram em exercícios dialógicos e caracterizaram um movimento de estudo exploratório materializando um ato de cuidado ao buscar sentir o que o outro sente e, desse modo, sensibilizar pesquisador e pesquisados da importância do trabalho de pesquisa como ação ética, estética e política. Nesse processo, a empatia se estabeleceu a partir da apresentação do projeto e sua finalidade que esclarecia a forma pela qual se chegou a essa escola, ou seja, sua indicação pelas boas e bem-sucedidas práticas desenvolvidas.

Ressalta-se que esse primeiro movimento antecedeu aos encaminhamentos técnicos ne-

6 Original em espanhol. Tradução e comentário entre parênteses das autoras. 
cessários a realização de pesquisa (autorização dos órgãos gestores). Posteriormente, de acordo com a aceitação e acolhimento das instituições e sua abertura à pesquisa, definiu-se como campo um conjunto de seis instituições públicas que reunia a primeira e a segunda etapa da educação básica, ou seja, educação infantil - creche e pré-escola - e ensino fundamental (anos iniciais) respectivamente.

Diante da concordância e aceite das instituições, foram submetidos ao órgão competente Secretarias Municipais de Educação (SME) e suas Coordenadorias Regionais (CRE) o projeto e pedidos de autorização para entrada e realização dos procedimentos de pesquisa.

Após a autorização, foi iniciada a aplicação das estratégias metodológicas propostas: o primeiro passo foi realizar, durante o ano letivo 2017/2018, a observação com registro em diários de campo com vistas a captar as boas práticas e experiências bem-sucedidas de cuidado de crianças e adultos entre si no interior das instituições e a relação com as famílias e responsáveis, e baseado nelas, identificar os sujeitos a serem entrevistados individual e/ou coletivamente.

Identificados os sujeitos, procederam-se diferentes estratégias metodológicas que foram definidas pelos pesquisadores a partir de condutas e comportamentos observados nos grupos. Sendo assim, com os responsáveis, que tinham diferentes graus de relação com as crianças: pais, avós e madrinhas, inicialmente, sugeriu-se a realização de entrevista coletiva, mas em face das dinâmicas cotidianas de cada um, em cada grupo, esse procedimento foi desenvolvido de acordo com as condições possiveis.

Por outro lado, com as crianças, a partir da sua concepção como pessoa em desenvolvimento, que opina, critica e sugere, o exercício de escuta do que ela tinha a dizer sobre cuidar e ser cuidado foi orientado pela apresen- tação da pesquisa e seus objetivos, com uma linguagem adequada às suas especificidades, bem como um pedido oral de autorização às crianças e escrito aos familiares para gravar em áudio a conversa estabelecida. Após esse procedimento, considerando a faixa etária, entre quatro e cinco anos, foram desenvolvidas oficinas tomando entre outros, o livro literário, como objeto de mediação para conversar, trocar ideias e experiências sobre cuidar e ser cuidado.

As oficinas foram desenvolvidas no interior das instituições, portanto, a escolha de local adequado, além da presença de um dos profissionais da escola a quem as crianças estavam familiarizadas foram pedidos feitos à equipe diretiva. Em todo esse processo, assumimos uma postura de pesquisa em que as crianças e adultos são compreendidos na perspectiva de atores sociais em que as preocupações e relações éticas entre pesquisador e informantes são as mesmas, quer se trate de conduzir a pesquisa com adultos ou com crianças. (FERREIRA, 2009).

A necessidade de respeitar e aceitar criança em sua especificidade e singularidade passa pelo reconhecimento das suas condições sociais e das diferenças daí decorrentes, a fim de que the sejam oferecidos os meios adequados para que possa viver o seu tempo, desenvolver-se, criar, imaginar e experimentar.

A partir da concepção da criança pequena e mais especificamente aquela na faixa etária de zero a cinco anos - como pessoa de pouca idade, que produz cultura, é nela produzida, brinca, aprende, sente, cria, cresce e se modifica, ao longo do processo histórico que constitui a vida humana e é constituída a partir de sua classe social, etnia, gênero e por diferenças fisicas, psicológicas e culturais (KRAMER; MOTTA, 2010), são tecidas a seguir algumas considerações teórico-metodológicas em torno da realização da oficina com quatro crianças de 
uma Emei, que atende a aproximadamente 115 crianças de três a cinco anos de idade, em dois turnos (manhã e tarde) e é considerada uma escola de referência do trabalho pedagógico na educação infantil do município.

\section{As observações das crianças na escola do Quintal}

A escolha desta escola como campo da pesquisa decorre de a mesma ter sido umas das instituições envolvidas em um programa de intervenção desenvolvido em parceria com a universidade a que o grupo de pesquisa está vinculado. 0 conhecimento das práticas aliado ao reconhecimento da rede municipal foram fatores que orientaram a escolha da escola e das profissionais entrevistadas.

O uso de nome fictício para identificação da escola e dos sujeitos foi um procedimento ético e cuidadoso de pesquisa adotado em todas as instituições pesquisadas e a escolha dos nomes das instituições se deu a partir de suas características ou de seu entorno. Diante disso, a escola ora apresentada foi identificada como Escola do Quintal.

$\mathrm{Na}$ Escola do Quintal, as entrevistas, seja com os profissionais ou com os familiares, foram individuais atendendo aos dias e horários sugeridos pelos sujeitos. A proposta foi a escuta de relatos, no entrecruzamento da experiência e rememoração de seu processo educativo e formação que implica cuidar e ser cuidado.

Sem desconsiderar as questões e dilemas, as observações na Escola do Quintal confirmaram os argumentos que orientaram a sua escolha como instituição com práticas positivas de cuidado nas relações entre a comunidade escolar. Observou-se que tanto as práticas com crianças, conversas e reuniões entre a equipe gestora e os profissionais, quanto a relação entre os profissionais, crianças e famílias, são permeadas por ações de cuidado das quais se destaca a relação dialógica com as famílias que, diariamente circulam pela escola, são reconhecidos e chamados por seus nomes, dialogam com as professoras e equipe gestora os problemas cotidianos e, participam ativamente das atividades propostas pela instituição conforme exemplificado no evento a seguir.

\section{O Show de talentos}

As crianças estão reunidas e sentadas no chão do pátio. Atrás delas, cadeiras à espera dos pais que, segundo a direção, foram convidados a participar do evento. As crianças e professoras esboçavam uma euforia e alegria: era o show de talentos.

Uma das professoras dá início e, após uma fala inicial, oferece às crianças a oportunidade de apresentarem seus talentos explicando que podem cantar, dançar ou fazer o que quiser. Nós nos sentamos junto às crianças onde também estavam as professoras. Algumas delas se aproximam de nós e pedem para sentar no colo, dentre elas, Erick e Lavínia.

Daqueles que incentivam os colegas, Erick se destaca: muito entusiasmado, ele vai indicando e incentivando os colegas a se apresentarem. Sugere e acompanha, mas não vai à frente.

- Por que você não vai? (perguntamos)

- Eu não. Eu tenho vergonha! Ele se vira para João e diz:

- Vai lá, cara. Canta um pagode... eles riem, mas nenhum dos dois vai.

Lucas e Mateus estão discutindo quem vai à frente. Enquanto conversam, Mateus se vira para nós, aponta para Lucas e diz:

- Ele é meu tio.

Lucas se mostra introspectivo e fala que não vai. Passados alguns minutos o sobrinho, após insistir muito, pega o tio pela mão e vão juntos. As crianças aplaudem e as professoras incentivam. Mateus pega o microfone, entrega a Lucas e the fala ao ouvido. Lucas canta uma cantiga de roda de mãos dadas com Mateus e as crian- 
ças os acompanham. (Caderno de Campo, obs/ EQ; 24/08/2017).

$\mathrm{Na}$ situação observada, destaca-se diferentes perspectivas de cuidado no respeito e valorização das individualidades das crianças seja por parte dos profissionais da escola, quando garantem a essas o direito de não se apresentar em uma conduta de acolhimento, reconhecimento e aceitação do outro, ou pelos pares como, por exemplo, quando Erick, junto às demais crianças e professoras, incentiva aos colegas, mas se reserva ao direito de não ir à frente. Por outro lado, Matheus, que mantém uma relação de familiaridade com Lucas não apenas o incentiva, mas se coloca ao seu lado, oferecendo-lhe confiança e reciprocidade em que não há uma busca pelo conhecimento do outro, mas uma relação com ele.

Observar as crianças e adultos numa perspectiva de escuta exige não apenas observá-las, mas ouvir o que elas tinham a dizer considerando que sobre a totalidade do aluno só influi verdadeiramente a totalidade do educador, sua existência toda, espontaneamente. (BUBER, 2004, p. 40).

Para Buber, "educação é relação", um exercício de "voltar-se para o outro como ele é" (2012, p. 93) e não como eu desejo que ele seja. Ela se abre para conhecer e reconhecer a singularidade dos sujeitos. De acordo com Bakhtin (2008, p. 309), o "diálogo exterior expresso é inseparável do diálogo interior" e, em certo sentido, nele se baseia.

Em seus escritos sobre a educação, Buber a concebe como preparação para o sentido de comunidade e, sendo assim, ela não pode ser teórica e só pode ocorrer através da comunidade, daquilo que os sujeitos experimentam juntos. Para isso, é preciso saber o que educa e quem educa. (PENA, 2019).

\section{As crianças e suas famílias}

Algumas crianças vão à frente, pegam o micro- fone e convidam aos pais para se apresentarem juntos.

Samuel pega o microfone e entusiasmado convida a mãe. A professora pega o microfone, apresenta a mãe e pede os aplausos. A mãe de Samuel aparece com uma fantasia de abelha, dança uma música religiosa ensinando às crianças a coreografia; algumas pareciam já conhecer. Ao final anuncia uma surpresa: ela e Samuel distribuem pirulitos para todas as crianças.

Durante esse período, a família de Lavínia, criança que estava sentada no nosso colo, chega. O pai, a mãe, o tio e a irmã vieram participar. O tio chega com uma bola. Lavínia corre ao seu encontro, o abraça, pega a bola e se encaminha para o microfone. Ela fala ao ouvido da professora que anuncia que Lavínia fará uma apresentação especial. Lavínia pega o microfone e convida o pai e o tio e juntos fazem embaixadinhas.

[...].

Os nomes de Cândida e Cláudia são aclamados pelas crianças e pelas professoras. Elas são convidadas a dançar e dançam junto às filhas e as demais crianças, funks atuais.

Após as apresentações, pais, professores e direção conversam e comentam as apresentações. O clima é de diálogo e interação. (Caderno de Campo, obs /EQ; 24/08/2017).

A escola se organiza de modo que haja espaço para o diálogo e escuta das famílias respeitando suas formas de organização, crenças e manifestações. $\mathrm{O}$ acolhimento e respeito favorecem tanto o diálogo quanto a alegria das crianças que se sentem valorizadas individual e coletivamente. Nesse contexto, o cuidado se imprime como atuação, preocupação, responsabilização e envolvimento afetivo com esse outro numa relação que educa cuidando e cuida educando, e, desse modo, constrói-se uma educação dialógica que implica responsabilidade e atualidade.

De acordo com Tristão (2008), independente da classe social, todas as crianças têm o di- 
reito de serem cuidadas/educadas e, acima de tudo, respeitadas como ser social, ativo, que possui interesses e vontades próprias. Para ela, todo o cuidado que recebe do outro, no caso, o adulto, é deveras necessário, pois é: "daquele que dela cuida, que tomará contato com suas primeiras impressões sobre o mundo, experimentando sensações agradáveis ou desagradáveis".

Uma educação alicerçada na relação, na reciprocidade e no diálogo implica a escuta e a resposta responsável como condutoras das relações e das práticas educativas, tendo em si mesma a potência de humanização. (KRAMER, 2013). Assim entendida, a educação de qualidade envolve a relação com o outro em prol da melhoria do mundo, nos humaniza, se ocupa das coisas simples, do ordinário, do comum. Essa educação implica, portanto, presença:

Olhar profundo que parecia tocar a intimidade de seu interlocutor, e que, contudo, sabia acolher na simplicidade e na fugacidade de um diálogo. Uma presença autêntica emanava de sua pessoa, e a profundeza de seu semblante residia na presença a si mesmo. Exatamente por esta presença a si mesmo é que ele podia tornar-se presente aos outros, acolhendo-os incondicionalmente em sua alteridade. (ZUBEN, 1974, p. XV-XVI).

\section{A oficina como estratégia de escuta das crianças}

A pesquisa com crianças é campo recente que se constrói na perspectiva de que elas têm o direito de serem ouvidas acerca de temas que the dizem respeito. Para Corsaro, ao entender as crianças como sujeitos, em vez de objetos de pesquisa e buscar a captura de vozes infantis, os pesquisadores não desenvolverão novos métodos que diferem dos métodos tradicionais utilizados para estudar adultos, mas precisarão refinar seus métodos e ajustá-los às "necessidades específicas e particularidades do grupo" (2011, p. 57).

Estruturada no pressuposto teórico-metodológico que considera relações contextualizadas em um movimento em que a língua é social e socializada e, portanto, diálogo, caminho de encontro e alteridade com a criança, pessoa em desenvolvimento, agente social que atua modificando as estruturas sociais em que se encontra, dando-lhes outros sentidos e que, portanto, tem uma história de vida, a pesquisa aqui apresentada se estruturou a partir da perspectiva de que escutar a criança em suas especificidades e exige compreender que sua apreensão da própria história é diferente dos adultos.

Para Spink, Menegon e Medrado, as oficinas “são práticas sociais de caráter discursivo cuja produção remete à negociação retórica de versões, apreendida a partir da dimensão performática do uso da linguagem, cujos efeitos são amplos e nem sempre associados a intenções originais" (2014, p. 34), nesse sentido, as oficinas com crianças podem ser compreendidas como estratégia metodológica que as entende como sujeitos de pesquisa.

A realização da oficina como estratégia metodológica foi utilizada na pesquisa para a escuta das crianças; enquanto com os adultos foram desenvolvidas entrevistas individuais e ou coletivas. Desse modo, se as observações e entrevistas com os adultos adquiriram contornos de mundo da experiência quando envolveram movimentos de contemplação e observação, na oficina, adultos e crianças buscaram, a partir da literatura, o mundo da relação e simultaneamente, a tomada de conhecimento intimo, o face a face, a exclusividade.

Nesse percurso, buscando conhecer as percepções das crianças de cuidar e ser cuidado, a literatura infantil, enquanto arte, foi tomada como mediadora na interação leitor (pesquisador) e ouvinte (crianças) de modo que múl- 
tiplos sentidos fossem construídos. Corsino (2015), ao abordar a literatura como arte a partir dos estudos de Mikhail Bakhtin afirma que:

A multiplicidade é parte e exigência do contemporâneo. E, para não ter limites, depende dos processos imaginativos de cada um. Este inacabamento é justamente o que abre possibilidades, do múltiplo: multiplicidade de gêneros, abordagens, estilos, suportes. Se há uma estrutura que sustenta a literatura, há uma arquitetônica que recria, reinventa e surpreende. (p. 122)

A presença da literatura na oficina remete ao movimento dialógico que, segundo Buber (2014), acontece na relação Eu-Tu-isso. Diante disso, na posição de pesquisador, assume-se inicialmente a necessidade de que a relação entre o Eu - pesquisador - e o isso - dados de pesquisa -, seja aporte para a construção da relação Eu-Tu em que se estabelece o diálogo.

Buber (2014) aponta três maneiras de perceber o outro: observação, contemplação e tomada de conhecimento íntimo que permitem pensar a pesquisa dialógica. 0 observador quer gravar o homem em sua mente, sendo necessária uma atenção excessiva e ater-se a tantos detalhes quanto possivel. 0 contemplador é livre dessas "amarras" e espera despreocupado aquilo que a ele se apresentará. 0 observador e o contemplador têm em comum o desejo de perceber o homem que vive diante de seus olhos; esse homem é para eles um objeto separado deles próprios e das suas vidas pessoais. A tomada de conhecimento íntimo requer uma postura receptiva, uma disponibilidade, um aceitar, um ver o outro não como um objeto. (PENA, 2019).

As observações das interações com os pares e a consulta às profissionais da escola nortearam a definição das crianças convidadas a participar da oficina. Definidos os sujeitos, o processo de agendamento e a realização dos procedimentos metodológicos foram construí- dos considerando as condições de organização e funcionamento da instituição.

Inicialmente, a proposta foi a escuta de seis crianças na oficina, mas em virtude do não comparecimento dos responsáveis para a autorização, a oficina que durou aproximadamente 90 minutos contou com quatro crianças e aconteceu em uma tarde no espaço da sala de vídeos, onde havia uma televisão, um aparelho de DVD e almofadas.

Anterior ao início da oficina, uma das diretoras trouxe brinquedos e livros, e lembrou as crianças a proposta do encontro. Para iniciar a conversa, as pesquisadoras que já eram conhecidas das crianças, apresentaram o objetivo da oficina acompanhado do pedido verbal de consentimento para gravar em áudio. A partir do assentimento das crianças, procedeu-se a leitura da história Um tanto perdida, de Chris Haugton (2011).

A oficina se constituiu em um momento de interação e trocas entre crianças/crianças e crianças/pesquisadoras que trouxeram relatos e vivências de cuidado de si e do outro.

o livro, escolhido previamente pela aproximação da perspectiva de cuidado assumida na pesquisa, narra a experiência de um filhote que se "perde" de sua mãe e, em sua busca encontra um grupo de voluntários que o acolhe, escuta, entra em relação com ele e o auxilia em sua procura. Durante a narração, as crianças faziam intervenções interagindo com a história contada e, a partir dela, iniciou-se um diálogo abordando o que pensavam sobre cuidar e ser cuidado. E, em suas perspectivas, cuidar e ser cuidado se relacionam às relações familiares e à brincadeira conforme descrito no diálogo a seguir:

EMANUELE: A mãe da coruja não cuidou dela. LÉO: Cuidou sim.

ENT: Por quê?

EMANUELE: Porque ela não viu que a corujinha estava fugindo. 
ENT: E o que é cuidado?

EMANUELE: Cuidar é não deixar ninguém sair. Para ninguém pegar. Para ninguém pegar, assim.

ENT: Cuidar é isso, Léo? Quem cuida de você?

LÉO: Minha mãe, meu pai, meus irmãos.

ENT: Por que eles cuidam?

LÉO: Eles cuidam de mim porque eu sou o filho deles.

ENT: Então, quem cuida?

EMANUELE: A mãe, o pai, o tio, o avô e a avó.

LÉO: $E$ irmão.

ENT: E você, cuida de quem?

LÉO: Eu cuido de quem? Dos meus brinquedos $e$ da minha família.

ENT: Então, o que é cuidar?

LÉO: Cuidar é não quebrar as coisas. Cuidar é tomar cuidado.

ENT: O que é tomar cuidado?

LÉO: Para não quebrar o brinquedo. Eu tenho um avião. E ele é de plástico porque ele estraga. EMANUELE: Tem que ter cuidado com coisa que é de vidro. A coisa é de ferro, que machuca. Todas as coisas que machuca. Cuidar é a pessoa cuidar de gente. (Caderno de Campo, oficina/EQ; 29/06/2018)

A oficina possibilitou a construção coletiva do conhecimento, de análise da realidade quando Léo e Emanuele, que tinham cinco anos, apresentam percepções distintas de cuidar e ser cuidado que ressignificam discursos recorrentes da relação com os adultos, como por exemplo quando as relacionam a proteção familiar entendida como presença, ou tomar cuidado com objetos e bem-estar o que remete ao cuidado técnico. A literatura, por outro lado evoca uma percepção de cuidado que é acolhimento, atenção, reciprocidade, relação que Emanuele define como "Cuidar é a pessoa cuidar de gente".

O cuidado enquanto binômio indissociável das propostas pedagógicas de educação infantil não foi apontado pelas crianças, exceto quando inquiridos pelas pesquisadoras.

ENT: E aqui na escola quem cuida de vocês? EMANUELE: A professora.
ENT: A professora cuida de você?

EMANUELE: Cuida, cuida muito.

ENT: Como é que a professora cuida de você? EMANUELE: Para não sair.

ENT: Cuidar é tomar conta?

EMANUELE: É.

LÉO: Para não sair? A gente tem que sair um pouquinho para viver!

(Caderno de Campo, oficina/EQ; 29/06/2018)

A escuta das crianças e análise dos dados produzidos a partir das oficinas implicaram a necessidade de criar outras categorias, pois as suas percepções de cuidar e ser cuidado tanto se aproximaram das concepções dos adultos quanto se referiam às suas experiências infantis. Assim, foram definidas as seguintes categorias: cuidado como atenção (acolhe o erro); cuidado como carinho; cuidado que falta (para elas ou amigos); cuidado como ofício do professor (algo simples que importa para a criança); cuidado de pessoas (merendeiras, avós); cuidado como brincadeira. (KRAMER, 2019).

\section{Considerações}

Os dados de pesquisa apresentados convidam a reflexão do que é cuidado e, questionamento de que se, por estar impresso em documentos orientadores da prática educativa como binômio indissociável do educar, ele parece "instrumentalizado" e revestido de um caráter utilitário que desconhece a criança como um Tu no trabalho cotidiano da educação infantil.

Cuidado é ato que implica atuação e essa exige presença e reciprocidade e, portanto, ação humana e humanizante que reconhece a criança, pessoa em desenvolvimento que, portanto, observa, sente, narra, opina e percebe todo ato de cuidado ou descuido.

Concordamos com Guimarães quando assinala que cuidar não envolve só habilidade técnica, mas atenção, reflexão, contato e leva 
em conta o componente emocional. Cuidar envolve afetividade, atenção ao outro e "ao mesmo tempo, apesar de cuidado relacionarse com reflexão, não se restringe ao campo da introspecção, mas implica também atitudes para com o outro, podendo dirigir-se a coisas ou pessoas; portanto, voltando para si e para o mundo". (GUIMARÃES, 2011, p. 46).

Acolhimento, relação, reciprocidade e diálogo são palavras que afetam diretamente a relação educativa, aqui propositadamente chamada de relação, pois no que se refere à educação de crianças pequenas se faz necessária e urgente a compreensão de que as práticas cotidianas com elas construídas sejam estruturadas no diálogo a fim de que Eu e Tu se afetem e atuem nessa relação e o risco da desumanização que, cotidianamente nos ameaça, seja superado.

Entender o cuidado como diálogo e relação é de fato construir novas formas de sociabilidade e de subjetividade comprometidas com o rompimento de relações de dominação em uma sociedade em que prevalece o egoísmo, a individualidade e relações que deixam a margem o encontro entre o Eu/Tu e as relações se caracterizam apenas como Eu/ isso.

Pesquisar o cuidado é movimento de resistência e resgate das experiências que humanizam os sujeitos quando se reconhecem como seres coletivos que vivem e convivem em comunidade, sem querer impor ao outro a sua própria realização. (BUBER, 2014). Ressaltar o lugar do cuidado na prática entre os homens é, na verdade, uma busca por provocar o sentimento de comunidade com vistas a superar a ideia de coletividade que, fundamenta-se numa atrofia organizada da existência pessoal; “[...] uma fuga da pessoa diante da prova e da consagração da comunidade, diante da dialógica vital que está no coração do mundo e que exige o engajamento de si-mesmo". (BUBER, 2014, p. 66-67).
Nesse sentido, a observação de práticas cuidadosas entre crianças e adultos, crianças e crianças, adultos e adultos, no contexto escolar, direcionou a definição dos dispositivos metodológicos adotados no desenvolvimento da pesquisa. Essas considerações podem ser pensadas na perspectiva da pesquisa nas ciências humanas, visto que tem nas relações humanas o seu objeto, seus sujeitos e na escola um dos seus possiveis campos científicos.

Desse modo, sugere-se uma metodologia que aposta nas relações, no cuidado, na opção de entrar em contato com os sujeitos, estabelecer diálogos, lidar com o desafio da alteridade, do conhecimento do outro. E, nessa relação, os dispositivos metodológicos são ressignificados a partir do cuidado em um movimento de encontro, no qual a tomada de conhecimento íntimo resulta em uma postura receptiva, ou seja, observar, escutar e aceitar o outro na sua inteireza.

o percurso construído no desenvolvimento da pesquisa se configurou por meio das observações de crianças e adultos numa perspectiva de escuta que exigiu não apenas observá-los, mas ouvir o que tinham a dizer e possibilitaram a identificação de práticas de respeito às individualidades entre crianças, profissionais e familiares.

Entendida como dispositivo metodológico que possibilita a construção coletiva do conhecimento, a análise da realidade e implica o exercício de escuta que desconstrói uma hierarquização das relações e saberes, a adoção de oficinas na pesquisa com crianças se configura a partir de sua concepção como pessoa em desenvolvimento, que brinca, fantasia, imagina, opina, critica, sugere e, portanto, pressupõe uma linguagem adequada às suas especificidades, considerando sua faixa etária, seus interesses e condições para que se sinta segura e acolhida. Nesse movimento, o livro literário configura um dos possiveis obje- 
tos de mediação para conversar, trocar ideias e experiências e, pode, como afirma Corsino (2015, p. 102716), ampliar "as possibilidades de conhecer a si mesmo, o outro e mais um pouco do mundo para além do que já conhecido, de organizar experiências, de imaginar e criar, de pensar, de se emocionar, de apreciar a estética dos textos verbal e visual e suas interrelações".

\section{Referências}

BAKHTIN, Mikhail. Estética da criação verbal. São Paulo: Martins Fontes, 2011.

BAKHTIN, Mikhail. Problemas da poética de Dostoiévski. Tradução de Paulo Bezerra. Rio de Janeiro: Forense Universitária, 2008.

BAKHTIN, Mikhail. Estética da criação verbal. Tradução feita a partir do francês por Maria Ermantina G. G. Pereira. São Paulo: Martins Fontes, 1992a.

BAKHTIN, Mikhail. (Volochinov). Marxismo e filosofia da linguagem. 6a ed. São Paulo: Hucitec, 1992b.

BOFF. Leonardo. Saber Cuidar. Ética do Humano Compaixão pela Terra. Petrópolis: Vozes, 1999.

BRASIL/ Brasil. Ministério da Educação. Secretaria de Educação Básica. Secretaria de Educação Continuada, Alfabetização, Diversidade e Inclusão. Secretaria de Educação Profissional e Tecnológica. Conselho Nacional da Educação. Câmara Nacional de Educação Básica. Diretrizes Curriculares Nacionais Gerais da Educação Básica / Ministério da Educação. Secretaria de Educação Básica. Diretoria de Currículos e Educação Integral. Brasília: MEC, SEB, DICEI, 2013.

BRASIL/MEC/CNE/SEB. Diretrizes curriculares nacionais para a Educação Infantil. Brasília, DF:MEC/ CNE/SEB, 2009.

BRASIL/MEC/SEB. Parâmetros nacionais de qualidade para a Educação Infantil. Volume I. Brasília, DF: MEC/SEB, 2006a.

BRASIL/MEC/SEB. Parâmetros nacionais de qualidade para a Educação Infantil. Volume II. Brasília, DF: MEC/SEB, 2006b.
BRASIL/MEC. Ministério da Educação e do Desporto. Diretrizes Curriculares Nacionais para a Educação Infantil. Brasília, DF, 1999.

BRASIL/MEC. Lei de Diretrizes e Bases da Educação Nacional, no Lei no 9.394, de 20 de dezembro de 1996.

BRASIL. Lei federal n. 8.069 de 13 de julho de 1990. Estatuto da criança e do adolescente. Brasília, DF: [s.n.], 1990

BUBER, Martin. Eu e Tu. Tradução do alemão, introdução e notas ZUBEN, N. 2.ed. São Paulo: Moraes, 1974.

BUBER, Martin. Eu e Tu. Trad. e introdução de Newton Aquiles Von Zuben. São Paulo: Centauro, 2001.

BUBER, Martin. El caminho del ser humano y otros escritos. Salamanca: Kadmos, 2004.

BUBER, Martin. Do diálogo e do dialógico. São Paulo: Perspectiva, 2014.

CORSARO, William. A Sociologia da Infância. São Paulo: Artmed, 2011.

CORSINO, Patrícia. Infância e Literatura: entre conceitos, palavras e imagens. Revista Teias. Rio de Janeiro: n. 41, 2015, p. 108-123. Disponivel em: https:// www.e-publicacoes.uerj.br/index.php/revistateias/ article/view/24516/17496. Acesso em: 29/04/2020. Acesso em: 10 mar. 2020.

CORSINO, Patrícia. Leitura literária na escola e produção de sentido. In: XVII ENDIPE - Encontro Nacional de Didática e Prática de Ensino, 2014, Fortaleza/ CE. Anais, EdUECE, 2015, p.102713-102721. Disponivel em: http://www.uece.br/endipe2014/ebooks/livro1/310. Acesso em: 10 mar. 2020.

FERREIRA, Maria Manuela Martinho. "Branco demasiado" ou... Reflexões epistemológicas, metodológicas e éticas acerca da pesquisa com crianças. In: SARMENTO, Manuel Jacinto; GOUVEIA, Maria Cristina Soares de. (Orgs). Estudos da infância: educação e práticas sociais. Petrópolis: Vozes, 2009. p. 143-162.

FREITAS, Maria Teresa Freitas; SOUZA, Solange Jobim; KRAMER, Sonia. (Orgs.). Ciências humanas e pesquisa: Leituras de Mikhail Bakhtin. 2.ed. São Paulo: Cortez, 2003. 
GERALDI, João Wanderley. 0 texto na sala de aula. 3. ed. São Paulo: Ática, 2003.

GUIMARÃES, Daniela. Relações entre bebês e adultos na creche: o cuidado como ética. São Paulo: Cortez, 2011.

HAUGTON, Chris. Um tanto perdida. São Paulo: Atica,2011.

KRAMER, Sonia. et al. Relatório final da pesquisa "Linguagem e rememoração: crianças, famílias, professores/as e suas histórias". Apresentado à Fundação Carlos Chagas Filho de Amparo à Pesquisa do Estado do Rio de Janeiro - FAPERJ, dez. 2019.

KRAMER, Sonia. Educação como resposta responsável: apontamentos sobre o outro como prioridade. In: FREITAS, M. T. (org.). Educação, vida e arte em Bakhtin. Belo Horizonte: Autêntica, 2013b, pp. 29-46.

KRAMER, Sonia; SANTOS, Tânia. Regina Lobato dos. Contribuições de Lev Vigotski para a pesquisa com crianças. In: MARCONDES, Maria Inês; OLIVEIRA, Ivanilde; TEIXEIRA, Elizabeth. (Orgs). Abordagens teóricas e construções metodológicas na pesquisa em Educação. Belém: EDUEPA, 2011. p. 17-36.

KRAMER, Sonia; MOTTA, Flávia Miller Naethe. Criança. In: OLIVEIRA, Dalila Andrade; DUARTE, Adriana Cancella; VIEIRA, Lívia Fraga. DICIONÁRIO: trabalho, profissão e condição docente. Belo Horizonte: UFMG/Faculdade de Educação, 2010. CDROM

KRAMER, Sonia. Profissionais de Educação Infantil: gestão e formação. São Paulo: Ática, 2005.

KRAMER, Sonia. (Org.). Ciências humanas e pesquisa: Leituras de Mikhail Bakhtin. São Paulo, Cortez, 2003.

KUHLMANN JR., Moysés. O jardim de infância e a educação das crianças pobres: final do século XIX, início do século XX. In: MONARCA, Carlos (Org.). Educação da infância brasileira: 1875-1983. Campinas, SP: Autores Associados, 2001. p. 3-30. (Coleção Educação Contemporânea).

KUHLMANN JR., Moysés. Infância e Educação. Infantil: uma abordagem histórica. 3 ed. Porto Alegre: Mediação, 2004.

PENA, Alexandra Coelho. "Toda vida atual é encontro": contribuições de Martin Buber para a Educação. Educação, Porto Alegre, v. 42, n. 3, set.-dez, 2019, p. 506-513. Disponivel em: https://revistaseletronicas.pucrs.br/ojs/index.php/faced/article/ view/29874. Acesso em: 10 mar. 2020

TRISTÃO. Fernanda Carolina Dias. Cuidado é Educação: o trabalho com bebês. Revista Avisa lá, n. 33, 2008, [S.I.]. Disponivel em: http://avisala.org. br/index.php/assunto/jeitos-de-cuidar/cuidado -e-educacao-o-trabalho-com-bebes/. Acesso em: 29/04/2020.

ZUBEN, Newton Aquiles Von. Introdução e Notas do Tradutor. In: BUBER, Martin. Eu e Tu. 2a ed. São Paulo: Moraes, 1974, p. I-LXXIII.

SPINK, Mary Jane; MENEGON, Vera Mincoff; MEDRADO, Benedito. Oficinas como estratégia de pesquisa: articulações teórico-metodológicas e aplicações ético-políticas. Psicologia \& Sociedade, 26, 2014, p. 32-43. Disponivel em: https:// www.scielo.br/scielo.php?script=sci_arttext\&pi$d=S 010271822014000100005 \&$ lang=pt. Acesso em: 10 mar. 2020

Recebido em: 30/04/2020 Revisado em: 08/08/2020 Aprovado em: 18/08/2020

Rejane Brandão Siqueira é doutora em Educação pela Pontificia Universidade Católica do Rio de Janeiro (PUC-Rio). Professora do curso de especialização lato sensu Educação infantil: perspectivas de trabalho em creches e pré-escolas e na Secretaria de Estado de Educação (Seeduc) do Rio de Janeiro. Membro do grupo de pesquisa Infância, Formação e Cultura (Infoc) da PUC-Rio. E-mail: rejsiqueira@gmail.com

Rosiane B. Siqueira Alves é doutoranda em Educação pela Pontificia Universidade Católica do Rio de Janeiro (PUC-Rio), mestre em Educação pela PUC-Rio, especialista em Educação Infantil por essa mesma universidade e em História Contemporânea Universidade Federal Fluminense (UFF). Professora da Secretaria de Estado de Educação (Seeduc) do Rio de Janeiro. Membro do grupo de pesquisa Infância, Formação e Cultura (Infoc) da PUC-Rio. E-mail: rosianebranda014@gmail.com 